\title{
New Aspects of the Teen Suicide
}

\author{
Oksana Chekstere*, Larysa Kondratenko, Lydia Manylova
}

G.S. Kostiuk Institute of Psychology, NAPS of Ukraine, Kyiv, Ukraine

How to cite this paper: Chekstere, O., Kondratenko, L., \& Manylova, L. (2017). New Aspects of the Teen Suicide. The Educational Review, USA, 1(4), 91-93. http://dx.doi.org/10.26855/er.2017.04.002

*Corresponding author: Oksana Chekstere, Ph.D, G.S. Kostiuk Institute of Psychology, NAPS of Ukraine, Kyiv, Ukraine.

\begin{abstract}
In this article the problems of child and teen suicide were considered. Its characteristic features are revealed and analyzed. It is noted that the psychology of communication in this age is based on the contradictory interweaving of two needs: separation (privatization) and affiliation, that is, the need for belonging, inclusion in a particular group or community. First of all it concerns groups of the teenagers, united directly by the theme of suicide. The authors investigated the so-called "death groups" in social networks, where interest in suicide becomes not personal, but a group norm, while an attempt to commit suicide greatly increases group authority, where successful attempts are recognized within a group's feat. The authors draw attention to the false notions and myths that exist in the consciousness of many teenagers regarding suicides.
\end{abstract}

\section{Keywords}

Teen Suicide, Social Networking, Child Suicide

\section{Introduction}

Teen suicid e belongs to such terrible and painful phenomena, which, although make tragic impression, is often considered by society as exclusively personal tragedy. Despite this fact, from time to time there is a sharp increase of the teen suicides, which is becoming epidemic. Thus, in the very beginning of the XX century through the Russian Empire swept a wave of school boys. Only according to the official data in 1904, 44 pupils of secondary schools committed suicide, in 1907-74 pupils, in 1908 - 83, in 1909-143, that is, for 4 years 274 children voluntary attempted suicide. In this case society couldn't consider suicide as single phenomenon, and therefore began the wide discussion both by the general public and by the scientific community. Unfortunately, in the Soviet Union period the problem of teen suicide was in the number of "unwished" for conducting researches, that is the reason why extensive study of this phenomenon began only with the advent of the era of "perestroika" (Russian: перестройка). The conducted studies allowed to reveal the main causes of suicidal actions of teens.

\section{Methodology}

As the background for the development of the suicidal behavior could serve conflicts in the family, when the child feels being extra, useless. In addition, there are emotional deafness of parents, misunderstanding by parents of the imperative needs of the child, indifference to his/her problems and experiences, family violence, divorce of parents or complex relationships between them. The feeling of loneliness is becoming deeper in the case of absence or of limited circle of friends with whom it would be possible to discuss all the problems. On this background, an impulse to suicide can act as a real problem, which a teenager cannot share with his parents or friends (bullying or peer support, persecution or physical/sexual abuse by a third-party adult, for the first time felt and realized his unconventional sexual orientation , 
unlucky love, financial inability to meet their needs, etc.), and absolutely small, fleeting frustrations (bad evaluation of a good student, an insult to an adult or the same teenager, fear of punishment, fall of the press I'm having unfair accusations and even a minute's desire to "punish" an adult) everything can be a boost to teenage suicide. That is why children's suicide is so difficult to prevent. However, in all the cases of "traditional" teen suicide self-destroyer had his/her own inner intentions to commit this action.

\section{Findings and Discussion}

However, the new type of suicide appeared now, main distinction from traditional suicide is that self-destroyer often doesn't have nor objective, neither subjective reasons for this action, notably-even her/his own intention to do it. In essence, it is a suicide only in form but not in context. We are talking about suicide as an element of a certain mysterious game in which the player gradually performs more and more complex tasks: first, a simple drawing on his hand, then causing himself physical damage, carrying out actions related to the risk to life (to cross the road as close as possible to the car, jump from the roof to the roof of the neighboring buildings, ride on the dash of the tube of the train) and to end (so-called quest), actually with a suicide, which takes place in the form of "flight" from the last floor of a multistory building. All stages of the game are photographed, filmed and posted on the Internet.

The final stage is being filmed by two - the future self-destroyer by himself is filming the view before the jump and observer - the result of the jump.

To understand the logic of actions of members of networks' "groups of death" is quietly complicated. Their explanations are confused and inconsistent. They say they play the game, because it's cool, it's possible to prove that you are "special", not like the rest.

Surveyed by the staff of the Laboratory of Psychodiagnosis and Scientific and Psychological Information of the G.Kostyuk Institute of Psychology, a fourteen-year-old boy who stopped following the quest only when he gained the last task of the quest, said that he was not very respected in school, and when he became a member "group of death" the attitude of classmates to him changed.

He showed up correspondence, demonstrated tasks and was proud of himself. But eventually he got more and more scared. However, it was very difficult to give up the game, because he understood that classmates, having learned about it, would most likely laugh at him. Yet, the fear of death was stronger and he tried to get out of the group. However, the game administrator began to send him an SMS message threatening to revenge. Fortunately, the teenager was wise enough to turn for help to the cyber police. The IP address of the computer was changed, just in case the hard disk was formatted, and the sim card of the phone was replaced.

What makes teens like him to participate in this game? Children of this age are characterized by the desire to assert himself, become someone important, find a group of friends who would recognize his "feature". If he does not find such friends in the real world, he begins to look for them in the virtual one. Deep in the veil of social networks, he can gradually lose touch with reality, falling into the so-called "dissociative trans" [John Suler] and in this state he sharply reduces the criticality of perception, he is easily subjected to suggestions and manipulations with his consciousness.

In addition, virtual games create the illusion of "plurality of life" or even "no existence of death". Such a teenager, jumping from the roof of the house, in fact, until the end does not believe in his own death, he assures himself that he or someone will rescue, or he simply "will fly to another world where everything will be better".

According to the data of cyber police of Kiev, at least 13 thousands of teenagers in Ukraine are members of the "death groups", but there are 260 members who are considered to be active and constant members. 


\section{Conclusion}

As in the case of a traditional suicide, the best propaedeutics of such a deed is the establishment of a really warm, friendly relationship in the family, the lack of appreciation of the child, the provision of social comfort outside the family, the creation of an environment in which he could fully discover and did not need to seek recognition in the virtual the world. Unfortunately, even the warmest family relationships do not fully guarantee the safety of children in the Internet and prevent them from involvement in the "game of death", a bright and exciting the computer world of fantasy. They can't resist the attractiveness virtuality can create a no less vivid and exciting reality, raising the status of a child in real life, attracting to sports and social activities.The role of the Corporate Multilateral Agencies in offering opportunities for sustainable improvement of learning outcomes of Tanzanian children is evident, recognized, and important. Despite unique difficulties met by the literacy interventions, they have been marked on the whole by some achievements in promoting reading culture by providing readers. However, the literacy interventions remain short term alternatives to literacy development. Therefore, this paper makes a strong appeal to the Corporate Multilateral Agencies, Tanzanian government, and communities to support, sustain and institutionalize the literacy innovations to keep pace with the 2030 agenda of ensuring equitable, inclusive and quality education as well a vision 2025.

\section{References}

Aleksandrov ,Y. (2013). The Problem of Child Suicide. Scientifical Works IAMP, 4, 195-200. (Ukrainian)

Krupska, N. K. (1963). Self-sufficiency of the Means of Education and Labor School. Pedagogical Work: In 10 Volumes-K.: Radianska School, 1, 131-138. (Ukrainian)

Yurchenko, O. (2013). Child Safety Problems in Social Networks and Internet (Victimological Aspect). Comparing and Analitical Law, 3-1, 336-338. (Ukrainian) 